DOI: $10.4274 /$ jarem.galenos.2020.3600

J Acad Res Med 2020;10(2):185-8

\title{
The Efficacy of Voice Therapy in Call Center Agents with Disphonia
}

\author{
(1) Maral Yeşilyurt, (1) Kürşat Yelken \\ Üsküdar University Faculty of Health Sciences, Department of Speech and Language Therapy, İstanbul, Turkey \\ Cite this article as: Yeşilyurt M, Yelken K. The Efficacy of Voice Therapy in Call Center Agents with Disphonia \\ J Acad Res Med 2020;10(2):185-8
}

\begin{abstract}
Objective: In this prospective research, voice therapy results of 13 call center employees with voice problems were evaluated.

Methods: Thirteen call center employees (13 women) with voice problems who underwent voice therapy between September 2012 and January 2013 were included in the study. All patients underwent videolaryngostroboscopy prior to voice therapy. Before and after therapy, voice recordings were analyzed with Praat Program, voice handicap index-10 (VHI-10), maximum phonation time (MPT), s/z ratio values and diet passage readings for perceptual evaluation (GRBAS) were obtained. The results were statistically compared.

Results: Statistically significant differences between VHI, MPT and $s / z$ ratio and GRBAS was obtained before and after voice therapy ( $p<0.05)$.

Conclusion: Call center employees who experience voice problems benefit from voice therapy while the existing workload density continues.

Keywords: Voice therapy, voice disorder, call center
\end{abstract}

\section{INTRODUCTION}

Vocation-related voice problems are most common (38\% to $80 \%)$ in teachers $(1,2)$. The second occupational group followed by $68 \%$ are call center employees (3). The first call center was established in the late 1960s by a federal judge's decision by the Ford firm to allow customers to report faulty cars to the company (4). The Call Centers Association states that the number of customer representatives in call centers reached ninety-one thousand people in 2017 and that they expect the number to rise to ninety-five thousand people in 2018 (5). Studies on call centers have shown that working in Call Centers is a stressful job (6). Tüfekçioğlu (7) stated that $37.7 \%$ of call center customer representatives experienced hoarseness in a study conducted in three different regions in Turkey. The voice complaints that occur in professional voice users such as call center employees are mostly hoarseness, tonal deterioration, narrowing of the voice range, weakness in the voice, and voice fatigue $(3,8,9)$. The accompanying complaints are shortness of breath, feeling stuck in the throat, feeling dry in the throat, sore throat and difficulty talking $(3,8,9)$. Chronic vocal problems can lead to benign vocal cord pathologies. Muscular tension dysphonia develops due to the misuse of the voice during phonation and habitual behaviors that are harmful to the voice. The tension in the neck muscles is noticeable to the eye even when talking, and the voice comes out tense, hoarse and muffled. Vocal nodules are associated with excessive or improper use of voice. The nodule is a small white or greyish protrusion located in the anterior $1 / 3$ on the

ORCID IDs of the authors: M.Y. 0000-0001-7454-6338; K.Y. 0000-0001-8133-2717.

Corresponding Author: Maral Yeşilyurt, E-mail: maral.yesilyurt@uskudar.edu.tr
Received Date: 13.07.2020 Accepted Date: 28.07.2020

(C) Copyright 2020 by University of Health Sciences Turkey, Gaziosmanpaşa Training and Research Hospital. Available on-line at www.jarem.org 
free edge of the vocal cords. Vocal cord polyps are unilateral lesions in contrast to vocal nodules. The Reinke cavity is located under the epithelium layer of the vocal cords. Reinke edema is a bilateral diffuse polyposis of this cavity. In later stages, the polypoid feature can progress enough to disrupt breathing. Its etiology includes smoking, allergies and chronic irritation (1012).

In this study, the call center employees who experienced voice problems and who were diagnosed with vocal nodules, muscle tension dysphonia, reinke edema, vocal polyps and vocal cysts as a result of larengostroboscopic evaluation were investigated whether they benefit from voice therapy while their workload intensity continued.

\section{METHOD}

In this prospective study, 37 patients who applied to İstanbul Anatomica Hospital with the complaint of hoarseness and were diagnosed with vocal nodule, muscle tension dysphonia, Reinke edema, vocal polyps, vocal cysts as a result of ear nose throat examination and video-laryngostroboscopic evaluation between September 2012 and January 2013 were included. The data of 13 clients who completed voice therapy were evaluated from these clients. Data from 24 clients who did not complete the therapy were excluded from the study.

Laryngeal structures of all clients were evaluated by an otolaryngologist during rest, flat / i / and glide-containing / i / fonation with videolaryngostroboscopy. Objective and subjective voice assessments of the clients were made before and after therapy. Maximum phonation time (MPT), s/z ratio, FO, intensity, jitter, shimmer, HNR parameters were examined from objective evaluations; aerodynamic and acoustic parameters. The Praat program was used in acoustic analysis of voice. In subjective evaluations, the client's voice was evaluated by voice handicap index (VHI-10) and the client's voice was evaluated by two clinicians with GRBAS. In the MPT evaluation, the clients were asked to expirate with /i/ vocal after a deep inspiration, and this process was repeated three times. The scores from each client were averaged. In order to evaluate the $s / z$ ratio of aerodynamic parameters, individuals were asked to expirate with /s/ and /z/ consonants after a deep inspiration, and this process was repeated 3 times. The scores from each client were averaged.

Within the scope of voice therapy, vocal hygiene and diaphragm breathing training were given in two groups, but voice exercises and laryngeal massage were applied to each client in the form of a specific therapy program. Voice therapy was performed 1 time per week. Each session lasted 35-40 minutes and a total therapy period of 4 weeks.

Within the scope of vocal hygiene training; the clients were informed about different forms of vocal rest, suggestions to prevent reflux, not speaking in noisy places, resting the voice occasionally while talking, avoiding extreme behaviors related to phonation, speaking at the middle pitch and violence level, increasing hydration, avoiding substances-foods and drinks that could harm the sound. The diet and medical treatment of the clients suffering from reflux was started by the ear nose throat physician.

\section{Statistical Analysis}

SPSS package program was used for statistical analysis of the findings. Statistical analysis of changes before and after voice therapy was evaluated using paired sample t-test in SPSS program. $P$ values less than 0.05 were considered statistically significant.

\section{RESULTS}

Thirteen (100\%) of the clients included in the study were women. Reinke edema was found in 1 of the clients, polyp in 1, muscle tension dysphonia in 3 , bilateral vocal nodules in eight. When the values obtained before and after voice therapy were compared, a statistically significant difference was obtained $(p<0.05)($ Table $1-3)$.

\section{Table 1. Acoustic values before and after therapy}

\begin{tabular}{|l|l|l|l|l|l|}
\hline & Before therapy & After therapy & t-value & p-value \\
\hline F0 & 217 & 212 & 0.726 & 0.482 \\
\hline Intensity & 90 & 91 & -1.554 & 0.146 \\
\hline Jitter & 0.22 & 0.15 & 3.081 & 0.010 \\
\hline Shimmer & 1.24 & 0.72 & 2.576 & 0.024 \\
\hline HNR & 20 & 24 & -2.725 & 0.018 \\
\hline
\end{tabular}

Table 2. Pre-and post-therapy MPT, $s / z, \mathrm{VHI}-10$ values

\begin{tabular}{|l|l|l|l|l|}
\hline & Before therapy & After therapy & t-value & p-value \\
\hline MPT & 13 & 18 & -6.624 & 0.000 \\
\hline S/z & 1.3 & 1.1 & 1.342 & 0.204 \\
\hline SHI-10 & 13 & 9 & 3.679 & 0.003 \\
\hline MPT: Maximum phonation time, VHI: Voice handicap index & & & \\
\hline
\end{tabular}




\begin{tabular}{|l|l|l|l|l|l|}
\hline \multicolumn{2}{|l|}{ Table 3. Pre-and post-therapy GRBS scores } & & After therapy & t-value & p-value \\
\hline g & Before therapy & 1.1 & 3.207 & 0.008 \\
\hline r & 1.6 & 1 & 4.382 & 0.001 \\
\hline b & 1.6 & 1 & 0.562 & 0.584 \\
\hline a & 1 & 0 & - & 5.500 & - \\
\hline s & 0 & 0.5 & 6.218 & 0.000 \\
\hline Total GRBAS & 1.4 & 3.7 & 0.000 \\
\hline
\end{tabular}

\section{DISCUSSION}

Voice therapy can be defined as an effort to restore the voice to the highest level possible to meet the occupational, emotional and social needs of the patient (13). In our study, VHI-10, GRBAS, MPT, s/z ratio, F0, intensity, jitter, shimmer, HNR parameters data obtained before and after the therapy of adult clients with vocal cord nodule, vocal cord polyps, reinke edema and muscle tension dysphonia statistically compared.

Bengisu et al. (10) found a statistically significant difference in jitter and shimmer parameters after the therapy compared with the pre-therapy in 19 of 20 patients with muscle tension dysphonia. de Oliveira et al. (14) found significant improvement in jitter values with voice therapy in their study with forty-eight call center employees, but they could not reveal a difference in other acoustic analysis parameters or perceptual evaluation scores. The results we found in the study show a similarity in the significant statistical changes seen in the jitter and shimmer parameters compared to previous publications.

Treole and Trudeau (15) found that 13 clients with bilateral vocal nodules had no statistically significant difference in MPT and s/z ratio compared with pre-therapy and post-therapy. Eryılmaz et al. (16) had statistically significant differences in VHI-10, MPT and $\mathrm{s} / \mathrm{z}$ ratio compared with pre-therapy and post-therapy of 40 adult clients with vocal cord nodules. Unlike the research of Treole and Trudeau (15), in our study, a statistically significant difference was found in the MPT values after the therapy compared with the pretherapy. When our results are compared with the results of the studies of Eryılmaz et al. (16), The significant statistical changes seen in SHI-10 and MPT scores show a similarity.

Holmberg et al. (17) administered voice therapy to eleven clients with bilateral vocal nodules. As a result, they found that voice therapy had a positive effect on perceptual evaluation and voice quality.

Symptoms such as feeling stuck in the throat and need for frequent throat clearing of mucus, even if there were no serious voice complaints in Call Center employees (18). In this study conducted by Lehto et al. (18), It was found that more than $60 \%$ of the employees had a change in their vocal habits, and no negative results were found in any subject receiving therapy. In their subsequent study, the same group of researchers questioned the long-term vocal complaints of their patients who underwent short-term therapy 1-1.5 years later by questionnaires and found significant improvement in complaints such as hoarseness and vocal tension compared to the group who did not receive therapy (19).

\section{CONCLUSION}

As a result, in our study, a statistically significant improvement was obtained in the jitter, shimmer and HNR parameters, VHI-10, MPT, general GRBAS and GRBAS sub-scores, $g, r$ and s-scores, compared before and after voice therapy $(p<0.05)$.

Ethics Committee Approval: Ethics committee approval was not received. Informed Consent: It was obtained.

Peer-review: Externally peer-reviewed.

Author Contributions: Concept - M.Y., K.Y.; Design - M.Y., K.Y.; Data Collection and/or Processing - M.Y., K.Y.; Analysis and/ or Interpretation - M.Y., K.Y.; Literature Search - M.Y., K.Y.; Writing Manuscript - M.Y., K.Y.

Conflict of Interest: The authors have no conflict of interest to declare.

Financial Disclosure: The authors declared that this study has received no financial support.

\section{REFERENCES}

1. Sapir S, Keidar A, Mathers-Schmidt B. Vocal attrition in teachers: survey findings. Eur J Dis Commun 1993; 28: 177-85.

2. Smith $\mathrm{E}$, Lemke J, Taylor M, Kirchner HL, Hoffman H. Frequency of voice problems among teachers and other occupations. J Voice 1998; 12: 4808.

3. Jones K, Sigmon J, Hock L, Nelson E, Sullivan M, Ogren F. Prevalence and risk factors for voice problems among telemarketers. Arch Otolaryngol Head Neck Surg 2002; 128: 571-7.

4. Bagnara S, Marti P. (2001) Human work in call centres: A challenge for cognitive ergonomic. Theoretical Issues in Ergonomics Science, 2001; 2: 223-37.

5. http://www.cagrimerkezleridernegi.org/haber-detay/3954/ erişim tarihi: 5.10.2018.

6. Taylor P, Bain P, "An assembly line in the head: Work and employee relations in the call center", Industrial Relations Journal 1999; 30: 101-17.

7. Tüfekçioğlu EY. 3 Farklı bölgedeki çağrı merkezi çalışanlarında genel sağlık durumu ve tükenmişlik düzeyi (dissertation). İstanbul ÜniversitesiCerrahpaşa Tıp Fakültesi 2015.

8. Smith E, Gray SD, Dove H, Kirchner L, Heras H. Frequency and effects of teachers' voice problems. J Voice. 1997; 11: 81-7.

9. Yiu EML. Impact and prevention of voice problems in the teaching profession: embracing the consumers' view. J Voice. 2002; 16: 215-28.

10. Bengisu S, Topbaş $S$, Koçak I. The relationship between muscle tension dysphonia type 1 and soft phonation index and the effectiveness of voice therapy. Kulak Burun Bogaz Ihtis Derg 2008; 18: 131-8.

11. Çobanoğlu B, Koçak I. Benign vocal cord lesions and treatment update. J Med Updates 2012; 2: 76-80. 
12. Yelken K. Psikojen ve diğer davranışsal ses bozuklukları. İçinde: Kılıç MA editors. Klinik ses bozuklukları. Adana Nobel Kitabevi 2012. s.166-92.

13. Kılıç M. Ses bozukluklarının tedavisi. İçinde: Kılıç MA editors. Klinik Ses Bozuklukları. Adana Nobel Kitabevi 2012. s. 231-70.

14. de Oliveira AG, Gouveia N, Behlau M. The effectiveness of a voice training program for telemarketers. J Voice 2012; 26: 815.e1-815. e8158.

15. Treole K, Trudeau MD. Changes in sustained production tasks among women with bilateral vocal nodules before and after voice therapy. J Voice 1997; 11: 462-9.
16. Eryılmaz A, Müjdeci B, Acar A. Results of voice therapy in vocal nodules In adults. Bozok Med 2014; 1: 6-11.

17. Holmberg EB, Hillman RE, Hammarberg B, Södersten M, Doyle P. Efficacy of a behaviorally based voice therapy protocol for vocal nodules. J Voice 2001; 15: 395-412.

18. Lehto L, Rantala L, Vilkman E, Alku P, Bäckström T. Experiences of a short vocal training course for call-centre customer service advisors. Folia Phoniatr Logop 2003; 55: 163-76.

19. Lehto L, Alku P, Bäckström T, Vilkman E. Voice symptoms of call-centre customer service advisers experienced during a work-day and effects of a short vocal training course. Logoped PhoniatrVocol 2005; 30: 14-27. 